\title{
Evaluation of the Indicators of Quality and Safety Using the Global Models of Pharmacy Accreditation in Iranian Pharmacies
}

\author{
Shahram Akbari (iD) ${ }^{1}$, Kamran Hajinabi (iD) ${ }^{1,}{ }^{*}$ and Leila Riahi ${ }^{1}$ \\ ${ }^{1}$ Department of Health Services Management, Science and Research Branch, Islamic Azad University, Tehran, Iran \\ "Corresponding author: Department of Health Services Management, Science and Research Branch, Islamic Azad University, Tehran, Iran. Email: hajinabi@srbiau.ac.ir
}

Received 2021 May 15; Revised 2021 May 25; Accepted 2021 May 27.

\begin{abstract}
Background \& Objective: Utilizing optimal accreditation methods in pharmacies could improve quality and safety. The present study aimed to evaluate the quality and safety indicators of Iranian pharmacies based on the global models of pharmacy accreditation.

Methods: The first phase of the study was exploratory, followed by descriptive, comparative, cross-sectional, analytical stages using the structural equation modeling technique. A regular search was conducted in databases such as PubMed and Google Scholar, websites of other reputable organizations (WHO), and pharmacy accreditation organizations using various keywords, including accreditation program, pharmacy, quality, safety, model, and their Persian equivalents. In total, 1,217 sources and studies were identified, 199 of which were relevant to the research subject. Based on the objectives of the study, the identified sources were refined, and 10 models were finally analyzed using the structural equation modeling technique. In addition, exploratory factor analysis was performed in SPSS, and confirmatory factor analysis was performed in the AMOS software. The validity and reliability of the model were evaluated for the sample size of 300.

Results: The quality and safety indicators were determined to be professional ethics, correct principles of medication, quality improvement programs, monitoring of quality improvement programs and improvement of the results, safety programs, error reporting, and monitoring of safety programs.
\end{abstract}

Conclusions: Our study could be considered a tool to improve the performance of pharmacies.

Keywords: Accreditation Program, Pharmacy, Model, Safety, Quality

\section{Background}

The delivery of safe and high-quality health care services is challenging $(1,2)$. Today, healthcare organizations are faced with significant challenges due to competing needs for service delivery. An environment where economic, political, and legal incentives of healthcare providers are maintained through cost control and quality assurance is often rejected (3). Therefore, most healthcare managers and policymakers in the field of health, standardization, accreditation, and evaluation centers fail to provide proper oral health services (4).

In healthcare services, the provision of medical services to outpatients and inpatients is of paramount importance. Every country must have a national drug policy in order to ensure the supply of effective, safe, high-quality, and economical services that could be afforded by the government and community. Therefore, pharmaceutical policy reforms in developing countries are an important area of the healthcare sector (5).
Hospital pharmacies are in charge of controlling and supervising the drug use process and provide timely access to medications and ensure their safe, effective use by patients (6). In recent years, pharmaceutical professions have expanded significantly in terms of providing professional services and are currently recognized as a pillar of the healthcare system (7).

Compared to developed countries, pharmacies in Iran are very similar in performance to the pharmacies of the United States in the 1940s as their role is mainly summarized in the preparation and distribution of drugs and medical supplies, while their scientific and pharmaceutical relationship with hospital wards is quite limited. Therefore, it seems necessary for Iranian pharmacies and pharmacists to take steps toward improving the pharmaceutical and clinical services provided by pharmaceutical units in developed countries (8).

Patient safety is a critical challenge in the health system across the world. In the past two decades, the notion 
that the health system is not safe enough and needs improvement and upgrading has been examined globally (9). As a result, patient safety has become a pressing issue in the delivery and availability of health services in different countries (10).

Today, most managers and politicians in the field of the health, accreditation, and evaluation of healthcare providers consider quality improvement investable (11). Therefore, pharmacy management based on valid national and international standards could improve the efficiency and productivity of these units (12).

\section{Objectives}

Due to the lack of quality and safety dimensions in the evaluation guidelines of the pharmacies in Iran and the urgent need of these pharmacies to improve the quality of their services and keep pace with the other pillars of the health system, the present study aimed to systematically review the validation models of pharmacy accreditation in the world to design the quality and safety dimensions of pharmacy evaluation in Iran.

\section{Methods}

The first phase of our study was exploratory, followed by descriptive, comparative, and analytical stages. The research also had a cross-sectional design and was conducted using the structural equation modeling technique during 2019 - 2020.

A regular search was conducted in databases such as PubMed and Google Scholar, websites of other reputable organizations (WHO), and pharmacy accreditation organizations using various keywords, including accreditation program, pharmacy, quality, safety, model, and their Persian equivalents. As a result of the literature search and based on the defined inclusion and exclusion criteria, 1,217 sources and articles related to the research subject were identified. The inclusion criteria were English and Persian sources focused on the issue of pharmacy accreditation, presenting the model of an accreditation program in pharmacies, and publication during 2000-2020. We also attempted to select models from all over the world and the five continents.

Initially, the titles of the identified articles were reviewed based on the objective of the research, and 1,018 articles that were irrelevant or had duplicate titles were excluded from the study. At the next stage, the abstracts and full text of the 199 remaining articles were reviewed, and
189 studies were excluded due to the lack of pharmacy accreditation models. Finally, the identified sources were refined, and 10 studies that were relevant to the research subject were selected for further review. Data were extracted on the dimensions and items of the models, and a conceptual model was also obtained through the comparative assessment of these dimensions and items.

After the formulation of the conceptual model, the question arises as to whether the extracted conceptual model corresponds to the situation in Iran. Therefore, the initial questionnaire was designed and validated considering the order of the studies. Face validity was confirmed by surveying a panel of experts. In addition, the content validity index (CVI) and content validity ratio (CVR) were assessed by 15 experts. The Lawshe table was also applied to determine the minimum value of the CVR, which indicated that the expressions with the CVR numerical value of higher than $49 \%$ were significant (13). To review the CVI, the experts were asked to determine the relevance of each of the statements in the questionnaire based on the CVI of Waltz and Bausell. At this stage, the items with the CVI score of above $79 \%$ were accepted (14), and reviewed or deleted otherwise.

The questionnaire, which was approved in terms of content and form, was also reviewed and approved in terms of reliability. In order to evaluate the reliability, a questionnaire was sent to 30 healthcare professionals and experts in person. After completing the questionnaires, the common and valid Cronbach's alpha coefficient test was used, and the Cronbach's alpha was estimated at 0.853 , which confirmed the internal consistency of the questionnaire. Therefore, the questionnaire had acceptable reliability as well.

Data were collected using a researcher-made questionnaire, which was designed in accordance with the objectives of the research. The study was conducted nationally by selecting five different poles in Tehran, Kermanshah, Gilan, Razavi Khorasan, and Fars provinces. Following that, 60 questionnaires were randomly distributed in each province.

To determine the factors and the associated variables, an exploratory factor analysis was performed in SPSS. Before the exploratory factor analysis, KMO and Bartlett's tests were used to assess the hypothesis of community normality, evaluate the possibility of the exploratory factor analysis, and determine the adequacy of the sample size. In addition, the VARIMAX method was employed to rotate the factors. After the exploratory factor analysis, the factors and variables with a higher factor load of 0.5 were extracted. After the modification of the initial model, the confirmatory factor analysis was initiated.

The AMOS software was used to calculate the chi-square 
fit and goodness fit indices, relative Chi-square, and the mean square error index of the estimation error of the factors. After testing the variables and factors, the confirmatory factor analysis was performed, along with construct reliability and validity assessments. As a result, the final model of the pharmacy accreditation program for Iran was developed.

\subsection{Evaluation of Construct Reliability and Validity}

To evaluate convergence and discriminant validity, the following values were calculated. If the conditions in Table 1 were met, construct validity would be confirmed.

\begin{tabular}{|c|c|}
\hline & $\begin{array}{l}\text { Conditions for Establishing Reliability } \\
\text { and Construct Validity (11) }\end{array}$ \\
\hline Reliability & $\mathrm{CR}>0.7$ \\
\hline \multirow{5}{*}{ Convergence validity } & Factor loads must be meaningful \\
\hline & Standard Factor loads $>0.5$ \\
\hline & $\mathrm{CR}>\mathrm{AVE}$ \\
\hline & $\mathrm{AVE}>0.5$ \\
\hline & $\mathrm{MSV}<\mathrm{AVE}$ \\
\hline Discriminant validity & $\mathrm{ASV}<\mathrm{AVE}$ \\
\hline
\end{tabular}

According to the obtained results, CR was higher than 0.7 , which confirmed reliability. In addition, $C R$ was higher than AVE, and AVE was higher than 0.5, which confirmed the convergence validity of the factor. Finally, AVE was higher than MSV, and AVE was higher than ASV.

The sample population of the present study included the managers and experts of the Food and Drug Administration (FDA), accreditation experts, and pharmacists. Given the use of the structural equation modeling technique, a significantly larger sample size was required to achieve more stable estimates of the studied parameters and standard errors while maintaining the necessary power. Therefore, 300 experts were randomly selected as the final sample population.

\section{Results}

By reviewing the accreditation models that are employed globally, we could select 10 accreditation models, including the models suggested by the Utilization Review Accreditation Commission (URAC), the Board of Certification/Accreditation (BOC), Center for Pharmacy Practice Accreditation (CPPA), and the Wolters Kluwer Clinical Drug Information (WKCI) in the United States, as well as the models proposed by Ontario's College of Pharmacists (OCP) in Canada, the Pharmaceutical Society of Ireland (PSI), the Indian Pharmaceutical Association (IPA), the Malaysian Pharmaceutical Society (MPS), the Accredited Drug Dispensing Outlet (ADDO) in Tanzania, and the pharmacy evaluation program conducted by the FDA of Iran.

According to the obtained results, seven variables had a significant correlation with the relevant factor and remained in the model $(\mathrm{P}<0.01)$. Furthermore, the correlation-coefficient of one factor was considered standard and confirmed. Therefore, the results of the confirmatory factor analysis, which was the same model proposed by the researcher for the accreditation of Iranian pharmacies, consisted of one factor and seven variables. Table 2 shows the status of the valid accreditation models of pharmacies in terms of quality and safety.

Our findings indicated that the main quality and safety indicators were within a dimension known as quality and safety, which contained the variables that have been discussed below.

\subsection{Professional Ethics}

Professional ethics was considered to be an influential factor in the improvement of quality and safety with the factor load of 0.84 . This item could be observed in the models of BOC and pharmacy evaluation by the FDA of Iran.

\subsection{Correct Principles of Medication}

According to the obtained results, the correct principles of medication had the factor load of 0.92. This item could also be found in the models of OCP, IPA, PSI, and pharmacy evaluation by the FDA of Iran.

\subsection{Quality Improvement Programs (Program and Implemen- tation)}

The quality improvement programs had the factor load of 0.83 and could be observed in the MPS, OCP, CPPA, and BOC models.

4.4. Monitoring of Quality Improvement Programs and Outcome Improvement

The monitoring of quality improvement programs and outcome improvement had the estimated factor load of 0.78 , and the items have been integrated into the MPS, OCP, and CPPA models.

\subsection{Safety Programs (Program and Implementation)}

Safety programs had the factor load of 0.94 , and the item has been considered in the models of the MPS, OCP, CPPA, and BOC. 


\begin{tabular}{lccccccccc}
\hline Table 2. A Review of Accreditation & Models of Pharmacies in Terms of Quality and Safety & & & \\
\hline Factor & IPA & MPS & OCP & CPPA & URAC & BOC & WKCI & ADDO & PSI \\
\hline Quality & $*$ & $*$ & $*$ & $*$ & Target & $*$ & $*$ \\
Safety & No & $*$ & $*$ & Target & No & $*$ & No & No & Target \\
\hline
\end{tabular}

\subsection{Error and Incident Reporting}

The reporting of errors and incidents had the estimated factor load of 0.81 , and its item could be found in the MPS, OCP, and CPPA models.

\subsection{Monitoring of Safety Programs}

Monitoring of safety programs had the factor load of 0.81 , and the item was observed in the MPS, OCP, and CPPA models.

\section{Discussion}

The present study aimed to review the two basic issues of safety and quality particularly based on the experiments conducted by valid global models of pharmacy accreditation. According to the obtained results, the quality and safety dimensions of assessing pharmacies were within the framework of one dimension and seven related items, including professional ethics, correct principles of medication, quality improvement programs (program and implementation), monitoring of quality improvement programs and outcome improvement, safety programs (program and implementation), error and accident reporting, and monitoring of safety programs.

The reviewed studies and database search in the present study revealed no similar studies in Iran and the world. Alkhateeb et al. reported the absence of national bodies to accredit pharmacies despite the fact that the International Pharmacy Accreditation has become increasingly popular. IPAC may serve as a tool to ensure the specific recognition of the quality of pharmacy programs and enhance the quality of pharmacy education in various regions in the absence of unmet pharmacy-specific national accreditation (15). In another study, Alijanzadeh et al. (2009) evaluated the systems of the preparation, distribution, maintenance, control, and consumption of drugs in the teaching hospitals in Qazvin (Iran), stating that drug management and drug systems in pharmacies have numerous problems, highlighting the need for fundamental structural changes in this regard in order to dramatically increase the efficiency of hospital pharmacies (16). The present study also considered it essential to change the evaluation system of the pharmacies in Iran.

Our findings are consistent with several studies in this regard, such as the studies conducted by Gough and
Reynolds and Sunol, which have identified accreditation as a driver of quality improvement $(17,18)$. Furthermore, Frey et al. claimed that a community pharmacy accreditation program based on standardized quality could practice optimally to create and reinforce behavioral changes in the community and the pharmacy setting, thereby positively affecting patient care and medication safety (19).

In their research on the quality of pharmacy services, Bruchet et al. reported the key influential factors in this regard to be the neatness of the appearance of pharmacies and staff, service efficiency, the safety and reliability of the services/correct service provision, and building trust in the customers regarding the operation of pharmacies; in the mentioned study, the authors also discussed some of the possible problems and shortcomings (20). The results of the present study also indicated the importance of the quality and safety indicators in pharmacy evaluation, which is in line with the findings of Bruchet et al.

The results obtained by Wongpratat are consistent with our findings, indicating that the quality indicators developed by the Community Pharmacy Association (Thailand) have acceptable reliability. On the other hand, the quality scores determined by this quality tool were higher in the accredited community pharmacies compared to non-accredited community pharmacies (21).

Quality and safety are extremely important indicators of the performance of pharmacies, as well as the basis and purpose of accreditation in numerous accreditation models. The present study was inspired by valid global models and aimed to highlight the sensitivity of the issue by introducing quality and safety indicators. According to the findings, an important shortcoming of the Iranian evaluation model is inattention to the issue of quality improvement and safety. Our study provides a tool to improve the condition of pharmacies and reduce medication errors as a benchmark for the assessment of pharmacies. Furthermore, we have provided a comprehensive knowledge of the items with the greatest impact on the quality and safety of pharmacies.

\section{Footnotes}

Authors' Contribution: Study concept and design: SH. A., and K. H, and L R; Analysis and interpretation of data: SH. A., and K. H.; Drafting of the manuscript: SH. A.; Critical 
revision of the manuscript for important intellectual content: SH. A., K. H., and L. R.; Statistical analysis: SH A.

Conflict of Interests: There was no potential conflict of interest.

Ethical Approval: IR.IAU.SRB.REC.1398.070.

Funding/Support: There was no funding/support.

\section{References}

1. Heiwe S, Kajermo KN, Tyni-Lenne R, Guidetti S, Samuelsson M, Andersson IL, et al. Evidence-based practice: attitudes, knowledge and behaviour among allied health care professionals. Int J Qual Health Care. 2011;23(2):198-209. doi:10.1093/intqhc/mzq083. [PubMed: 21242158].

2. Damschroder LJ, Aron DC, Keith RE, Kirsh SR, Alexander JA, Lowery JC. Fostering implementation of health services research findings into practice: a consolidated framework for advancing implementation science. Implement Sci. 2009;4:50. doi: 10.1186/1748-5908-4-50. [PubMed: 19664226]. [PubMed Central: PMC2736161].

3. Ginter PM, Duncan WJ, Swayne LE. The strategic management of health care organizations. John Wiley \& Sons; 2018.

4. Tabrizi JS, Gharibi F. Primary healthcare accreditation standards: a systematic review. Int J Health Care Qual Assur. 2019;32(2):310-20. doi: 10.1108/IJHCQA-02-2018-0052. [PubMed: 31017069].

5. Kamat VR, Nichter M. Pharmacies, self-medication and pharmaceutical marketing in Bombay, India. Soc Sci Med.1998;47(6):779-94. doi: 10.1016/s0277-9536(98)00134-8. [PubMed: 9690824].

6. Eiland LS, Benner K, Gumpper KF, Heigham MK, Meyers R, Pham $\mathrm{K}$, et al. ASHP-PPAG guidelines for providing pediatric pharmacy services in hospitals and health systems. J Pediatr Pharmacol Ther. 2018;23(3):177-91. doi: 10.5863/1551-6776-23.3.177. [PubMed: 29970974]. [PubMed Central: PMC6027974].

7. Mossialos E, Courtin E, Naci H, Benrimoj S, Bouvy M, Farris K, et al. From "retailers" to health care providers: Transforming the role of community pharmacists in chronic disease management. Health Policy. 2015;119(5):628-39. doi: 10.1016/j.healthpol.2015.02.007. [PubMed: 25747809].

8. Ekhtiari S, Raeeszadeh M, Mostafavi SA. [The comparative evaluation of the procurement, distribution and administration of drug in pharmacies of Kermanshah city to the standard of Food and Drug Organization]. Razi Journal of Medical Sciences. 2017;24(159):30-8. Persian.

9. Donaldson LJ, Kelley ET, Dhingra-Kumar N, Kieny MP, Sheikh A. Medication without harm: WHO's third global patient safety challenge. Lancet. 2017;389(10080):1680-1. doi: 10.1016/S0140-6736(17)31047-4. [PubMed: 28463129].
10. Wakefield JG, McLaws ML, Whitby M, Patton L. Patient safety culture: factors that influence clinician involvement in patient safety behaviours. Qual Saf Health Care. 2010;19(6):585-91. doi: 10.1136/qshc.2008.030700. [PubMed: 20724390].

11. Alkhenizan A, Shaw C. Assessment of the accreditation standards of the Central Board for Accreditation of Healthcare Institutions in Saudi Arabia against the principles of the International Society for Quality in Health Care (ISQua). Ann Saudi Med. 2010;30(5):386-9. doi: 10.4103/0256-4947.67082. [PubMed: 20697166]. [PubMed Central: PMC2941252].

12. Sadeghi T, Gholamhoseinni N, Khoshab H, Seyed bagheri SH, Karami $\mathrm{M}$, Nouhi E, et al. [Assessment managers' and hospital staff knowledge and attitude to accreditation]. J Nurs Manag. 2016;5(2):9-17. Persian. doi: 10.29252/ijnv.5.2.9.

13. Lawshe $\mathrm{CH}$. A Quantitative approach to content validity. Personnel Psychology. 1975;28(4):563-75. doi: 10.1111/j.1744-6570.1975.tb01393.x.

14. Wynd CA, Schmidt B, Schaefer MA. Two quantitative approaches for estimating content validity. West J Nurs Res. 2003;25(5):508-18. doi: 10.1177/0193945903252998. [PubMed: 12955968].

15. Alkhateeb FM, Arkle S, McDonough SLK, Latif DA. Review of national and international accreditation of pharmacy programs in the gulf cooperation council countries. Am J Pharm Educ. 2018;82(10):5980. doi: 10.5688/ajpe5980. [PubMed: 30643306]. [PubMed Central: PMC6325464]

16. Alijanzadeh M, Mehrbanifar Z, Karbero AA, Peyrovian F. [System evaluation, procurement, distribution, maintenance, control and drug use in teaching hospitals of ghazvin]. EdrakJ. 2009;13(12-18). Persian.

17. Gough LA, Reynolds TM. Is clinical pathology accreditation worth it? A survey of CPA-accredited laboratories. Clin Perform Qual Health Care. 2000;8(4):195-201. doi: 10.1108/14664100010361746. [PubMed: 11189081].

18. Sunol R, Nicklin W, Bruneau C, Whittaker S. Promoting research into healthcare accreditation/external evaluation: advancing an ISQua initiative. Int J Qual Health Care. 2009;21(1):27-8. doi: 10.1093/intqhc/mzn045. [PubMed: 18835832].

19. Frey M, Trapskin K, Margolis A, Sutter S, Cory P, Decker C. Pharmacistreported practice change as a result of a statewide community pharmacy accreditation program.JAm Pharm Assoc (2003).2019;59(3):4039. doi: 10.1016/j.japh.2018.12.019. [PubMed: 30940517].

20. Bruchet $\mathrm{N}$, Loewen $\mathrm{P}$, de Lemos J. Improving the quality of clinical pharmacy services: a process to identify and capture highvalue "quality actions". Can J Hosp Pharm. 2011;64(1):42-7. doi: 10.4212/cjhp.v64i1.986. [PubMed: 22479028]. [PubMed Central: PMC3053192]

21. Wongpratat A, Arkaravichien W, Lertsinudom S. Quality of service determined by the community pharmacy association's quality indicators between accredited and non-accredited pharmacies in the northeastern part of Thailand. ISAN J Pharm Sci. 2015;11(2):99-112. 